\title{
FAKTOR RISIKO DIABETES MELLITUS DI PUSKESMAS MANGASA KOTA MAKASSAR
}

\author{
Junaidi $^{1}$, Ruslan Hasani ${ }^{2}$, Nuraeni Jalil ${ }^{3}$, Ramlah Dilla ${ }^{4}$ \\ 1 Poltekkes Kemenkes Makassar, J1. Monumen Emmy Saelan III, Tidung, \\ Rappocini, Makassar, 0411-868797. email: hasani.ruslan@gmail.com \\ 2 Poltekkes Kemenkes Makassar, Jl. Monumen Emmy Saelan III, Tidung, \\ Rappocini, Makassar, 0411-868797. email: hasani.ruslan@gmail.com \\ 3 Poltekkes Kemenkes Makassar, Jl. Monumen Emmy Saelan III, Tidung, \\ Rappocini, Makassar, 0411-868797. email: hasani.ruslan@gmail.com \\ 4 Poltekkes Kemenkes Makassar, J1. Monumen Emmy Saelan III, Tidung, \\ Rappocini, Makassar, 0411-868797. email: hasani.ruslan@gmail.com
}

\begin{abstract}
ABSTRAK
Latar Belakang: Diabetes Melitus adalah merupakan penyakit menahun yang diderita seumur hidup oleh penderitanya. Penyebab adalah genetik, gaya hidup, IMT, manajemen stres dan aktivitas fisik/olahraga.

Tujuan: Mengetahui faktor risiko kejadian DM. di Puskesmas Mangasa Kota Makassar.

Metode: Penelitian ini menggunakan deskriptif analitik dengan rancangan case control study. Tempat penelitian di Puskesmas Mangasa. Pelaksanaan penelitian tanggal 1 - 21 September 2020. Pengambilan sampel menggunakan Purposive Sampling. Besar sampel penelitian adalah 47 sampel terdiri dari 19 orang penderita diabetes melitus Type 2 dan 28 orang bukan penderita diabetes melitus.

Hasil: Hasil penelitian menunjukkan pola makan $p$ values $=0,028$, nilai $\mathrm{OR}=5,111(95 \%$ CI : 1,36-19,16), IMT $p$ values $=0,065$, nilai $\mathrm{OR}=0,242$ (95\% CI : 0,064-0,906), Manajemen Stres $p$ values $=0,496$ nilai $\mathrm{OR}=0,609$ (95\% CI : 0,149-2,484), dan aktivitas olahraga $p$ values $=0,090$ nilai $\mathrm{OR}=0,267(95 \% \mathrm{CI}: 0,071-1,007)$.

Simpulan: ada hubungan pola makan dengan kejadian DM, tidak ada hubungan IMT dengan kejadian DM, tidak ada hubungan Manajemen stress dengan kejadian DM dan tidak ada hubungan aktivitas olahraga dengan kejadian DM.

Saran: bagi masyarakat bahwa agar terhindar dari penyakit Diabetes Mellitus adalah dengan menjaga pola makan yang sehat dan menjaga indeks massa tubuh dalam batas normal serta tetap memperhatikan pengelolaan manajemen stres dan aktivitas olahraga.
\end{abstract}

Kata kunci: Diabetes Melitus IMT, Manajemen Stres, Olahraga, Pola Makan. 


\begin{abstract}
Background: Diabetes mellitus is a chronic disease that is suffered by the sufferer for life. Causes are genetic, lifestyle, BMI, stress management and physical activity / xercise.

Objective: The purpose of this study was to determine the risk factors for the incidence of DM. at the Puskesmas Mangasa, Makassar City.

Methods: This research method is descriptive analytic with a case control study design. Place of research at Puskesmas Mangasa. The research was carried out on 1- 21 September 2020. Sampling used purposive sampling. The sample size of the study was 47 samples.

Results: The results showed diet value OR $=5.111(95 \% \mathrm{CI}: 1.36-19.16), \mathrm{p}=0.028$, BMI OR value $=0.242(95 \%$ CI: 0.064-0.906), $\mathrm{p}=0.065$, Stress Management OR Value $=0.609$ (95\% CI: $0.149-2.484), \mathrm{p}=0.496$ and sports activities $\mathrm{OR}=0.267$ (95\% CI: $0.071-1.007), \mathrm{p}=0.090$.

Conclusion: The conclusion of this study is that there is a relationship between diet and the incidence of DM, there is no relationship between BMI and the incidence of DM, there is no relationship between stress management and the incidence of DM and there is no relationship between sports activities and the incidence of DM.
\end{abstract}

Keywords: Diet, BMI, Stress Management, Exercise, Diabetes Mellitus.

\section{PENDAHULUAN}

Diabetes Melitus (DM) adalah merupakan penyakit metabolik dengan ciri-ciri adanya hiperglikemik akibat kelainan sekresi insulin, kerja insulin atau keduanya (ADA, 2018).

Diabetes Melitus adalah merupakan penyakit menahun yang akan diderita seumur hidup oleh pasiennya (Perkeni, 2015).

Faktor penyebab seseorang terserang penyakit Diabetes Melitus adalah adanya riwayat keluarga menderita Diabetes Melitus, gaya hidup yang kurang sehat seperti kurangnya aktivitas fisik, merokok dan asupan nutrisi yang berlebihan serta kegemukan. Ada beberapa bahaya yang mengancam penderita DM apabila penyakitnya tidak tertangani dengan baik diantaranya dapat terjadi koma diabetik, penyakit jantung koroner dan Strok yang dapat mengancam nyawa pasien, terjadinya kebutaan akibat retinopati, nefropati diabetik dapat menyebabkan gagal ginjal akut. Demikian juga dengan neuropati diabetik dapat menyebabkan terjadinya luka pada kaki penderita DM (Perkeni, 2015). 
Akibat dari dampak yang tidak diinginkan maka penanganan DM sangat difokuskan kepada pemberian obat-obatan. Namun belakangan ini diketahui bahwa perubahan gaya hidup pasien sangat berperan dalam keberhasilan penanganan DM. Gaya hidup yang sehat berperan aktif dalam menentukan keberhasilan pengobatan pada penderita DM. Dengan pengendalian metabolisme yang baik, menjaga agar kadar gula darah berada dalam kategori normal, maka komplikasi akibat diabetes dapat dicegah/ditunda.

Prinsip penanganan DM saat ini dikenal dengan pilar pengelolaan DM, yaitu meliputi 1) edukasi 2) perencanaan makan 3) latihan jasmani dan 4) intervensi farmakologis atau obat-obatan. Estimasi terakhir Federasi Diabetes Internasional (IDF), terdapat 382 juta orang yang hidup dengan Diabetes di Dunia pada tahun 2013. Pada tahun 2035 jumlah tersebut diperkirakan akan meningkat menjadi 592 juta orang. Diperkirakan dari 392 juta orang tersebut 175 juta diantaranya belum terdiagnosis, sehingga terancam berkembang progresif menjadi komplikasi tanpa disadari dan tanpa pencegahan.

Prevalensi DM berdasarkan diagnosis dokter pada penduduk urur $\geq$ 15 tahun menurut Propinsi, Sulawesi Selatan mengalami peningkatan jumlah prevalensi dibanding pada tahun 2013 yaitu sebesar 1,9\% namun masih dibawah rata-rata nasional $2 \%$ (Riskesdas, 2018). Prevalensi Diabetisi di Puskesmas Mangasa Kota Makassar tahun 2019 adalah untuk Kelurahan Mangasa kasus DM sebanyak 149 orang, Kelurahan Gunungsari sebanyak 134 orang dan Kelurahan Mannuruki sebanyak 41 orang. Berdasarkan latar belakang di atas maka dirumuskan permasalahan yang akan diteliti adalah : “ Faktor prediktif apakah yang berhubungan dengan Kejadian DM di Puskesmas Mangasa Kota Makassar?”. Tujuan umum penelitian ini adalah untuk mengetahui faktor prediktif kejadian DM. di Puskesmas Mangasa Kota Makassar.

\section{METODE PENELITIAN}

Jenis penelitian yang digunakan pada penelitian ini adalah penelitian deskriptif korelasional dengan pendekatan case control study. Jumlah sampel sebanyak 47 orang. 
Pengambilan sampel penelitian menggunakan teknik purposive sampling. Sampel penelitian terdiri dari 19 orang penderita diabetes melitus Type 2 dan 28 orang bukan penderita diabetes melitus Pengumpulan data dilakukan pada tangga 1 sampai dengan 21 September 2020 di Puskesmas Mangasa Kota Makassar.

Alat pengumpulan data dirancang oleh peneliti sesuai dengan kerangka konsep yang telah dibuat. Instrumen yang digunakan adalah lembar kuesioner yang dibuat sendiri oleh peneliti, Pada jenis pengukuran ini peneliti mengumpulkan data primer secara formal kepada responden untuk menjawab pernyataan secara tertulis atau wawancara langsung. Dan pengukurannya menggunakan Skala likerts dimana variabel diantaranya (pola makan, IMT, manajemen stress dan olahraga).

\section{HASIL DAN PEMBAHASAN}

Berdasarkan hasil pengumpulan data yang dilakukan, maka dapat ditampilkan hasilnya sebagai berikut :

Tabel 1

Karakteristik Responden

\begin{tabular}{|c|c|c|c|}
\hline & Variabel & $f$ & $\%$ \\
\hline 1 & $\begin{array}{l}\text { Usia } \\
\text { a. Kurang } 50 \text { tahun } \\
\text { b. } 50-59 \text { tahun } \\
\text { c. } 60-70 \text { tahun } \\
\text { d. Lebih } 70 \text { tahun }\end{array}$ & $\begin{array}{c}2 \\
25 \\
16 \\
4\end{array}$ & $\begin{array}{c}4,3 \\
53,2 \\
34 \\
8,5\end{array}$ \\
\hline 2 & $\begin{array}{l}\text { Jenis Kelamin } \\
\text { a. Laki-laki } \\
\text { b. Perempuan }\end{array}$ & $\begin{array}{l}32 \\
15\end{array}$ & $\begin{array}{l}68,1 \\
31,9\end{array}$ \\
\hline 3 & $\begin{array}{l}\text { Tingkat Pendidikan } \\
\text { a. SMP } \\
\text { b.SMA } \\
\text { c. PT }\end{array}$ & $\begin{array}{l}13 \\
20 \\
14 \\
\end{array}$ & $\begin{array}{l}27,7 \\
42,5 \\
29.8 \\
\end{array}$ \\
\hline
\end{tabular}

Responden terbanyak berusia antara 50-59 tahun sebanyak 25 orang (53,2\%), sedangkan jenis kelamin yang terbanyak adalah berjenis kelamin lakilaki sebanyak 32 orang $(68,1 \%)$. Tingkat pendidikan responden terbanyak adalah berpendidikan SMA sebanyak 20 orang $(42,5 \%)$.

Tabel 2

Hubungan Pola Makan dengan

Kejadian DM di Puskesmas Mangasa

Kota Makassar

\begin{tabular}{|c|c|c|c|c|c|c|c|c|}
\hline \multirow{3}{*}{$\begin{array}{c}\text { Pola } \\
\text { Makan }\end{array}$} & \multicolumn{4}{|c|}{ Menderita DM } & \multicolumn{2}{|c|}{ Jumlah } & \multirow{3}{*}{$\begin{array}{c}\text { pvalu } \\
\text { es } \\
\text { OR }\end{array}$} & \multirow{3}{*}{$\begin{array}{c}\text { CI } \\
95 \%\end{array}$} \\
\hline & \multicolumn{2}{|c|}{ Ya } & \multicolumn{2}{|c|}{ Tidak } & & & & \\
\hline & $\mathrm{n}$ & $\%$ & $\mathrm{n}$ & $\%$ & $\mathrm{n}$ & $\%$ & & \\
\hline Kurang & 10 & 21,3 & 5 & 10,6 & 15 & 31,9 & 0,028 & $1,36-$ \\
\hline baik & & & & & & & & 19,16 \\
\hline Baik & 9 & 19,1 & 23 & 48,9 & 32 & 68,1 & 5,111 & \\
\hline Jumlah & 19 & 40,4 & 28 & 59,6 & 47 & 100 & & \\
\hline
\end{tabular}

Sumber : Data Primer, 2020

Pada tabel 2 diatas terlihat bahwa kejadian DM lebih banyak terjadi pada responden dengan pola makan kurang baik yaitu sebanyak 10 orang (21,3\%). sedangkan jumlah terbesar kejadian tidak DM terjadi 
pada responden dengan pola makan yang baik yaitu sebesar 23 orang $(48,9 \%)$. Nilai $p$ values $=0,028 \mathrm{OR}=$ 5,111 (95\% CI: 1,36-19,16).

Berdasarkan hasil uji staistik diatas didapatkan nilai $p$ values $=$ $0,028<\alpha \quad 0,05$ maka dapat disimpulkan bahwa Ha diterima dan Ho ditolak. Artinya ada hubungan antara pola makan dengan kejadian DM. Orang yang mempunyai pola makan yang kurang baik memiliki risiko 5,111 kali untuk menderita DM dibanding dengan orang yang mempunyai pola makan yang baik di Puskesmas Mangasa Kota Makassar.

Hasil penelitian ini sesuai dengan penelitian Verawati (2014) dan Dafriani (2017) yakni terdapat hubungan antara pola makan dengan kadar gula darah pada pasien DM di Instalasi Rawat Inap Rumah Sakit PKU Muhammadyah Semarang dengan $\mathrm{p}=0,001$. Pasien yang memiliki pola makan tidak teratur memiliki kadar gula darah lebih buruk dibandingkan dengan pasien yang memiliki pola makan tidak teratur. Hasil penelitian Tukloy (2014) \& Dafriani (2017) juga menyatakan hal yang sama dimana terdapat hubungan antara pola makan dengan kejadian DM dengan $\mathrm{p}=0,001$.

Pengelolaan makan pada pasien diabetes melitus membutuhkan kolaborasi yang baik antara dokter dan ahli gizi. Dokter berperan dalam penentuan diagnosis medis, jenis obat dan dosis yang tepat untuk kebutuhan seorang diabetisi. Ahli gizi berperan dalam menghitung kebutuhan zat gizi perhari dan mengaplikasikan hasil perhitungan kebutuhan zat gizi dalam bahan makanan sehari. Ketepatan pemberian obat dan perencanaan makan yang baik dapat menjaga kestabilan glukosa darah dan mencegah timbulnya komplikasi lebih lanjut pada pasien DM. Tingginya asupan kalori dapat menyebabkan obesitas dengan beberapa cara : pertama, tingginya asupan energi yang berasal dari protein, karbohidrat dan lemak akan menyediakan substrat untuk penyimpanannya. Kedua, konsumsi karbohidrat sederhana yang tinggi akan meningkatkan kadar insulin. Tingginya kadar insulin juga dapat berdampak pada peningkatan rasa lapar karena mampu menginduksi penurunan glukosa, saat glukosa dalam darah rendah maka seseorang akan sangat terdorong untuk mencari makanan yang tinggi energi sebagai 
kompensasinya (Muhammad, 2017).

Tabel 3

Hubungan IMT dengan

Kejadian DM di Puskesmas

Mangasa Kota Makassar, Tahun

2020

\begin{tabular}{|c|c|c|c|c|c|c|c|c|}
\hline \multirow[t]{3}{*}{ IMT } & \multicolumn{4}{|c|}{ Menderita DM } & \multirow{2}{*}{\multicolumn{2}{|c|}{ Jumlah }} & \multirow{3}{*}{$\begin{array}{c}\text { Pvalues } \\
\text { OR }\end{array}$} & \multirow[t]{3}{*}{ CI $95 \%$} \\
\hline & \multicolumn{2}{|c|}{$\mathrm{Ya}$} & \multicolumn{2}{|c|}{ Tidsk } & & & & \\
\hline & $\mathrm{n}$ & $\%$ & $\mathrm{n}$ & $\%$ & $\mathrm{n}$ & $\%$ & & \\
\hline $\begin{array}{c}\text { Kurang } \\
\text { baik }\end{array}$ & 10 & 21,3 & 23 & 48,9 & 33 & 70,2 & $\begin{array}{l}0,065 \\
0,242\end{array}$ & $0,06-0,91$ \\
\hline Baik & 9 & 19,1 & 5 & 10,6 & 14 & 29,8 & & \\
\hline Jumlah & 19 & 40,4 & 28 & 59,6 & 47 & 100 & & \\
\hline
\end{tabular}

Pada tabel 3 diatas terlihat kejadian penyakit DM lebih banyak terjadi pada responden dengan IMT Kurang baik (IMT $<18,5$ atau $>24,9$ ) sebesar 10 orang $(21,3 \%)$ sedangkan kejadian tidak DM lebih banyak terjadi pada responden dengan IMT Kurang baik yaitu sebesar 23 orang (48,9\%). Nilai $p$ values $=0,065 \mathrm{OR}=0,242(95 \%$ CI : 0,06-0,91).

Berdasarkan hasil uji statistik diatas didapatkan nilai $\mathrm{p}$ values $=0,065>\alpha$ 0,05 maka dapat disimpulkan $\mathrm{Ha}$ ditolak dan Ho diterima. Artinya tidak ada hubungan antara IMT dengan kejadian DM di Puskesmas Mangasa Kota Makassar. IMT yang normal merupakan faktor protektif terhadap kejadian DM.

Obesitas merupakan faktor yang berperan penting terhadap penyakit Diabetes Mellitus Tipe 2, dan juga dipengaruhi oleh aktivitas fisik yang dapat mengotrol kadar gula darah, glukosa akan diubah menjadi energi saat beraktivitas fisik sehingga mengakitbatkan insulin semakin meningkat dan kadar gula darah akan berkurang (Nasution et.al, 2018). Obesitas atau kegemukan menyebabkan berkurangnya jumlah reseptor insulin yang dapat bekerja di dalam sel pada otot skeletal dan jaringan lemak, hal ini dapat menyebabkan resistensi insulin. Obesitas menyebabkan respon sel beta pankreas terhadap peningkatan glukosa darah berkurang, selain itu reseptor insulin pada sel diseluruh tubuh termasuk diotot berkurang jumlah dan keaktifannya (kurang sensitif) (Kabuso, Adu \& Hinga, 2017).

Diabetes mellitus adalah penyakit yang terikat oleh gen dan gaya hidup. Reduksi sekresi dan daya kerja (kepekaan) insulin dilatarbelakangi oleh gen, sementara resistensi insulin dipengaruhi oleh berbagai gaya hidup. Obesitas adalah salah satu contoh gaya hidup yang telah diyakini banyak ahli sebagai penyebab primer yang independen (Felber \& Golay, 2002). 
Keberhasilan mengurangi berat badan hingga $10 \mathrm{~kg}$ bukan hanya berarti sukses memperbaiki, tetapi juga (kemungkinan besar) menormalkan kadar gula darah, disamping menurunkan kadar trigliserida dan kolesterol total sekaligus meningkatkan konsentrasi HDL; semuanya ini tentu saja akan mengerdilkan dampak glikosilasi dan oksidasi terhadap partikel LDL. Perlambatan perkembangan dini dan perluasan pembentukan plak pada pembuluh darah ialah buah dari perbaikan profil diatas (Durstine, et. al., 2002).

Tabel 4

Hubungan Manajemen Stres dengan Kebijakan DM di Puskesmas Mangasa

Kota Makasar Tahun 2020

\begin{tabular}{ccccccccc}
\hline \multirow{2}{*}{$\begin{array}{c}\text { Man } \\
\text { Strea }\end{array}$} & \multicolumn{3}{c}{ Menderita DM } & Jumlah & pvalues & $\mathrm{C}]$ \\
& \multicolumn{2}{c}{ Ya } & \multicolumn{2}{c}{ Tidak } & & & OR & 95 \\
\cline { 2 - 6 } & $\mathrm{n}$ & $\%$ & $\mathrm{n}$ & $\%$ & $\mathrm{n}$ & $\%$ & & \\
\hline Kurang & 14 & 29,8 & 23 & 48,9 & 37 & 78,7 & 0,496 & 0,1 \\
baik & & & & & & & 0,609 & 2,4 \\
Baik & 5 & 10,6 & 5 & 10,6 & 10 & 21,3 & & \\
Jumlah & 19 & 40,4 & 28 & 59,6 & 47 & 100 & & \\
\hline Sumber : Data Primer, 2020 & & & & &
\end{tabular}

Pada tabel 4 diatas terlihat bahwa manajemen stress yang kurang lebih banyak terjadi pada responden yang menderita DM yaitu sebesar 14 orang $(29,8 \%)$ demikian juga responden yang tidak DM juga lebih banyak memiliki manajemen stress yang kurang baik yaitu sebesar 23 orang (48,9\%). Nilai $p$ values $=0,496$, $\mathrm{OR}=0,609(95 \% \mathrm{CI}: 0,149-2,484)$.

Berdasarkan hasil uji statistik didapatkan nilai $p$ values $-0,496>\alpha$ 0,05 maka dapat disimpulkan bahwa Ho diterima dan Ha ditolak. Artinya tidak ada hubungan antara Manajemen Stres dengan kejadian DM di Puskesmas Mangasa Kota Makassar.

Penelitian ini tidak sejalan dengan dengan penelitian Trisnawati dan Setyorogo (2012) di Cengkareng dimana didapatkan orang yang memiliki manajemen stres yang kurang baik berisiko 4,43 kali mengalami Diabetes Melitus dibanding dengan orang yang memiliki manajemen stres yang baik.

Adanya peningkatan risiko DM pada kondisi stres disebabkan oleh produksi hormon kortisol secara berlebihan saat seseorang mengalami stres. Produksi kortisol yang berlebihan ini akan mengakibatkan seseorang sulit tidur, depresi, tekanan darah turun yang kemudian akan membuat individu tersebut menjadi lemas dan nafsu makan berlebihan. Oleh karena itu, ahli nutrisi biologi Talbott (2002) menjelaskan bahwa 
pada umumnya orang yang mengalami stres panjang juga akan mempunyai kecenderungan berat badan berlebih yang merupakan salah satu faktor risiko Diabetes Melitus.

\section{Tabel 5}

Hubungan Aktivitas

Olahraga dengan Kejadian

DM di Puskesmas

Mangasa

\begin{tabular}{|c|c|c|c|c|c|c|c|c|}
\hline \multicolumn{9}{|c|}{ Kota Makasar, Tahun 2020} \\
\hline Man & \multicolumn{4}{|c|}{ Menderita DM } & \multirow{2}{*}{\multicolumn{2}{|c|}{ Jumlah }} & \multirow{3}{*}{$\begin{array}{c}\text { pvalues } \\
\text { OR }\end{array}$} & \multirow{3}{*}{$\begin{array}{l}\mathrm{Cl} \\
95 \mathrm{C}\end{array}$} \\
\hline \multirow[t]{2}{*}{ Strea } & \multicolumn{2}{|c|}{ Ya } & \multicolumn{2}{|c|}{ Tidak } & & & & \\
\hline & $\mathrm{n}$ & $\%$ & $\mathrm{n}$ & $\%$ & $\mathrm{n}$ & $\%$ & & \\
\hline Kurang & 4 & 8,5 & 14 & 29,8 & 18 & 38,3 & 0,090 & $\overline{0,0}$ \\
\hline baik & & & & & & & 0,267 & 1,0 \\
\hline Baik & 15 & 31,9 & 14 & 29,8 & 29 & 61,7 & & \\
\hline Jumlah & 19 & 40,4 & 28 & 59,6 & 47 & 100 & & \\
\hline
\end{tabular}

Pada tabel 5 diatas terlihat kejadian DM lebih banyak terjadi pada responden dengan aktivitas olahraga teratur yaitu sebesar 15 orang (31,9\%) sedangkan kejadian tidak DM terjadi baik pada responden dengan aktivitas olahraga teratur dan tidak teratur yaitu masing-masing sebesar 14 orang $(29,8 \%)$. Nilai $p$ values $=0,090, \mathrm{OR}=0,267(95 \% \mathrm{CI}$ : 0,071-1,007).

Berdasarkan hasil uji statistik didpatkan nilai $p$ values $=0,090>\alpha 0,05$ maka dapat disimpulkan bahwa Ho diterima dan Ha ditolak. Artinya tidak ada hubungan antara aktivitas olahraga dengan kejadian DM di Puskesmas Mangasa Kota Makassar.
Dengan melakukan latihan fisik seperti berjalan santai, berenang, bersepeda atau senam dapat memberi manfaat bagi tubuh dan juga dapat menurunkan kadar glukosa darah. Selain itu, tubuh menjadi bugar, lebih mudah melakukan aktivitas, otot dan sendi menjadi lentur, stres berkurang, nafsu makan dapat terkontrol (Tandra, 2018).

Hasil penelitian ini berbeda dengan beberapa peneliti (Tall, 2002) yang berhasil membuktikan keterkaitan antara derajat keluaran energi dan kadar HDL. Peningkatan konsentrasi HDL dalam darah berbanding lurus dengan waktu, jarak, serta frekuensi olahraga dalam hitungan minggu (Durstine et al, 2002). Pengidap dyslipidemia harus rela memeras keringat agar nilai HDL dapat terdongkrak membuang energi sebanyak 1200-2200 kkal seminggu, paling tidak selama 12 minggu. Olahraga yang disandingkan dengan perubahan diet terbukti mampu memperbaiki profil lipoprotein, terutama pada mereka yang mengalami sindroma metabolik.

Demikian juga hasil penelitian acak terkendali (randomized controlled trial) terhadap penduduk kota Da Qing di Cina membuktikan bahwa olahraga 
berhasil menghambat perkembangan toleransi glukosa terganggu (TGT) menjadi DM tipe 2. Sementara itu, Diabetes Prevention Study (Tuomelehto, 2001) dalam penelitiannya selama 3,2 tahun terhadap populasi yang berisiko tinggi di Finlandia yang diobati melalui modifikasi diet dan olahraga membuktikan bahwa risiko DM pada populasi tersebut terpangkas sebesar $58 \%$. Olahraga dapat mengatur gula darah melalui tiga mekanisme berbeda, yaitu: (1) perangsangan akut transport glukosa otot, (2) penguatan - akut kerja insulin, dan (3) Upregulation jangka panjang jalur pengisyaratan insulin (insulin signaling) akibat latihan fisik secara teratur.

Olahraga bukan sekedar berfaedah menipiskan tumpukan lemak disekitar perut dan mengikis berat badan, tetapi juga berkhasiat memperbaiki kepekaan insulin serta pengendalian gula darah. Perbaikan kepekaan insulin adalah dampak dari pertambahan afinitas reseptor insulin dan penurunan kebutuhan akan insulin itu sendiri, sementara perbaikan pengendalian glukosa mengarah pada penundaan penebalan membran basal pembuluh darah, penambahan massa tubuh tak berlemak, serta peningkatan kapasitas kerja (Tuomilehto, et. al., 2001).

$$
\text { Tujuan olahraga adalah }
$$
menambah kebugaran kardiovaskuler sebagai upaya memperlambat penyakit pembuluh darah coroner, (2) menjaga kelenturan otot (3) mempertahankan kekuatan otot, (4) menumbuhkan atau menjaga mutu kehidupan, mengendalikan berat badan, dan (6) menambah kepekaan insulin, atau mengurangi keadaan hyperinsulinemia (Tuomilehto, et. al., 2001)

\section{KESIMPULAN DAN SARAN \\ Kesimpulan}

Berdasarkan hasil penelitian diatas, maka dapat disimpulkan nahwa ada hubungan pola makan dan indeks massa tubuh dengan kejadian DM di Puskesmas Mangasa Kota Makassar. Tidak ada hubungan manajemen stress dan aktivitas olahraga dengan kejadian DM di Puskesmas Mangasa Kota Makassar.

\section{Saran}

Saran bagi masyarakat bahwa agar terhindar dari penyakit Diabetes Mellitus adalah dengan menjaga pola makan yang sehat dan menjaga indeks 
massa tubuh dalam batas normal serta tetap memperhatikan pengelolaan manajemen stres dan aktivitas olahraga.

\section{DAFTAR PUSTAKA}

ADA. (2018). Update to The Standards of Medical Care in Diabetes 2018.

Durstine, J.L., Grandjean P.W., Cox, C.A., Thompson,P.D. (2002) Lipid, lipoproteins and exercise. J Cardiopulm Rehabil. 2002, 22: 385-398.

Felber,J.P. \& Golay, A. (2002). Pathways from obesity to diabetes, International Journal of Obesity, 26, Suppl 2 , S39-S45. doi:10.1038=sj.ijo.0802126

International Diabetes Federation. (2015). Online Version Of Diabetes Atlas Seventh Edition 2015. Retrived form http://oedg.at/pdf/1606 IDF Atlas 2015 UK.pdf

International Diabetes Federation. (2017). Online Version Of Diabetes Atlas Eight Edition 2015. Retrived form http://diabetesasia.org/content/d iabetes guildelines/IDF guidelines.pdf

Kabuso, R. A., Adu, A. A., \& Hinga, I. A. (2019). Faktor Risiko Kejadian Diabetes Mellitus Tipe Dua di RS Bhayangkara Kota Kupang. Timorese Journal of Public Health, Vol. 1, No. 1.

Kementrian kesehatan RI. (2018). Hasil utama riskesdas 2018, 61. https://doi.org/1 September
2020.

Muhammad, H. F. (2017). Obesitas Translasional. Yogyakarta: Gadja Mada University Press.

Nasution, L. K., Siaginan, A., \& Lubis, R. (2108). Hubungan Obesitas Terhadap Kejadian Diabetes Mellitus Tipe 2 Pada Wnita Usia Subur Di Wilayah Kerja Puskesmas Pintu Padan. Jurnal Muara Sains, Teknologi, Kesehatan dan Ilmu Kesehatan, Vol.2, No.1, hal. 240-246.

Perkeni, (2015). Konsensus Pengelolaan dan Pencegahan Diabetes Melitus Tipe 2 di Indonesia. PB Perkeni, Jakarta. Dafriani, P. (2017). Hubungan Pola Makan dan Aktifitas Fisik Terhadap Kejadian Diabetes Melitus di Poliklinik Penyakit Dalam RSUD dr. Rasidin Padang. NERS: Jurnal Keperawatan, Volume 13, No.2, Hal.70-77.

Talbott, S. (2002). The Cortisol Connection, why stress makes you fat and ruins your health and what you can do about it, $2^{\text {nd }}$ edition Alameta CA: Hunter House Publisher.

Tandra, H. (2018). segala sesuatu yang harus anda ketahui tentang diabetes. Jakarta: PT Gramedia Pustaka Utama

Trisnawati, S.K. dan Setyorogo, S. (2013). Faktor Risiko Kejadian DM tipe II di Puskesmas Kecamatan Cengkareng, Jakarta Barat. Jurnal Ilmiah Kesehatan, Vol. 5, No. 1.

Tukloy, M. (2014). Hubungan Pola Makandan Aktifitas Fisik dengan Kejadian DM tipe II di RSUD Karel Sadsuitubun Langgur Maluku Tenggara. STIK Makasar. 
Diakses

dari

https:www.scrib.com/document /320020582 tgl 18 September 2020

Tuomilehto, J. et al. (2001). Prevention of Type 2 Diabetes Melitus by Changes in Lifestyle Among Subjects with Impaired Glukose Tolerance. New Engl J Med. 1343-1350.

Verawati, R.R. (2014). Pola Makan Berhubungan dengan Kadar Gula Darah Pasien Diabetes Mellitus di Rumah Sakit PKU Muhammadiyah. Fakultas Ilmu Kesehatan : UMS. 